ISSN 0103-5150

Fisioter. Mov., Curitiba, v. 28, n. 2, p. 269-276, Apr./June 2015

Licenciado sob uma Licença Creative Commons DOI: http://dx.doi.org.10.1590/0103-5150.028.002.A007

\title{
Elderly individuals with increased risk of falls show postural balance impairment
}

\author{
Idosos com maior risco de quedas apresentam \\ déficit de equilíbrio postural
}

Márcio Rogério de Oliveira ${ }^{[a, b]}$,Thiago Tadashi Inokuti ${ }^{[a]}$, Nuno Noronha da Costa Bispo ${ }^{[b]}$, Deise Aparecida de Almeida Pires Oliveira ${ }^{[a, b]}$, Rodrigo Franco de Oliveira ${ }^{[a, b]}$, Rubens Alexandre da Silva Jr. ${ }^{[a, b] *}$

[a] Universidade Estadual de Londrina (UEL), Londrina, PR, Brazil

[b] Universidade Norte do Paraná (Unopar), Londrina, PR, Brazil

\section{Abstract}

Introduction: Falls are a serious public health problem. Objective: The aim of this study was to evaluate whether elderly individuals with increased risk of falls have a postural balance deficit, evaluated using a force platform during a one-leg stance. Materials and methods: The sample consisted of 94 physically independent elderly individuals from the EELO project. The instruments used were the Downton scale, in

* MRO: PhD student, e-mail: marxroge@hotmail.com TTI: grad., e-mail: tadashi878@hotmail.com NNCB: MSc, e-mail: nunofisio@hotmail.com DAAPO: PhD, e-mail: deisepyres@yahoo.com.br RFO: PhD, e-mail: rfrancoli@yahoo.com.br

RASJ: PhD, e-mail: rubensalex@hotmail.com 
order to assess the risk as well as the history of falls, and the force platform to measure postural balance through parameters from the center of pressure (COP). Results: Elderly individuals were split into two groups according to the score observed with the Downton scale: G1 - low fall risk (score $\leq 2$ ) - and G2 high fall risk (score $>2$ ). No differences were observed between the groups concerning gender $(P>0.05$, Chi Square test). On the other hand, individuals from G2 showed postural instability when compared to individuals from G1, and individuals from G2 showed higher values in all COP parameters analysed (MannWhitney test, $\mathrm{P}<0.05)$. Conclusion: It can be concluded that the Downton scale has sensitivity for identifying individuals with balance impairment as well as a risk of falls. Therefore, it may be suggested that this scale may be useful in primary health care for detecting falls in the elderly.

Keywords: Aging. Accidental falls. Postural balance. Rehabilitation.

\section{Resumo}

Introdução: As quedas são um grave problema de saúde pública. Objetivo: O objetivo do presente estudo foi avaliar se idosos com maior risco de quedas possuem déficit de equilíbrio postural, quantificado por meio de uma plataforma de força durante o teste de apoio unipodal. Materiais e métodos: A amostra foi constituída por 94 idosos fisicamente independentes integrantes do projeto EELO. Como instrumentos de medidas para a avaliação, foram utilizados a Escala de Downton, para determinar os riscos, e históricos de quedas e a plataforma de força, para quantificar o equilíbrio postural por meio dos parâmetros do centro de pressão (COP). Resultados: Os idosos foram alocados em dois grupos conforme o escore da Escala de Downton: G1 - baixo risco de quedas (escore $\leq$ 2) - e G2 - alto risco de quedas (escore $>2$ ). Não foram observadas diferenças entre os grupos quanto ao gênero ( $P>0,05$, teste do Qui Quadrado). Por outro lado, foi observado que indivíduos do grupo G2 apresentam maior instabilidade postural em comparação aos do grupo G1, por apresentar valores aumentados de todos os parâmetros do COP (Teste de Mann-Whitney, $P<0,05$ ). Conclusão: Pode-se concluir que a escala de Downton apresenta sensibilidade para discriminar indivíduos com déficit de equilíbrio e risco aumentado para quedas. Desta forma, pode-se sugerir que esta escala poderia ser adotada na atenção primária à saúde e nos programas preventivos de detecção de quedas em idosos.

Palavras-chave: Envelhecimento. Acidentes por quedas. Equilíbrio postural. Reabilitação.

\section{Introduction}

In Brazil, the rate of growth of the elderly population has been systematic and consistent. According to the Research National by Sample of Households, the country has a population of about 21 million people 60 years or older. In the period 1999-2009, the relative number of elderly increased from $9.1 \%$ to $11.3 \%$, occupying a significant proportion of Brazilian society (1). The relatively higher growth of the elderly population is the result of the high rate of fertility prevalent in the past compared to the present, and the reduction of morbidity and mortality. While the aging population means a changing age structure, an aging individual goes through a dynamic process that begins at birth and presents new needs for attention in public health care (2).
The growing number of elderly people in Brazil is a phenomenon that is also present in the city of Londrina, in which the elderly population increased from $3.41 \%$ in 1960 to $7.32 \%$ in 1991 and to $12.72 \%$ in 2010 (greater than the national average set at $11 \%$ ) (1). This tendency presents a worrying feature, which can be seen by the absence of a real improvement in living conditions for a large portion of these individuals. Moreover, contrary to what happened in developed countries, the greater elderly population happened rapidly in Brazil $(1,3)$.

With increased longevity, the individual goes through biological and neuromuscular changes that are reflected in their physical and mental health, especially in the increased fragility and higher prevalence of chronic degenerative diseases. One consequence of this stage of life is a reduction of muscle 
mass, muscle movements, motor coordination and balance. This is reflected in the decline of neuromotor functions, in addition to poor physical fitness in the elderly (4). These neuromuscular and balance alterations are risk factors for the occurrence of falls in the elderly. Fall events are common in the elderly, which contributes to increased morbidity and mortality as well as social isolation and decreased quality of life in this population (5).

The main risk factors associated with falls are postural instability, the environment, disturbances and the use of drugs (6). Thus, falls could be due to extrinsic and intrinsic factors. Extrinsic factors are related to environmental issues such as soil type and ambient lighting. On the other hand, the intrinsic factors are physiological changes related to aging, and the presence of comorbidities or medication use, which can cause postural imbalance $(6,7)$.

The maintenance of balance is promoted by the postural control system, considered to be a multifaceted interaction of the SNC and somatosensory, vestibular and visual functions (7). Unfortunately, with advancing age, the process of postural control can deteriorate due to biomechanical and neuromuscular changes resulting from aging. Few studies involving patients at high risk of falls and measures of postural balance with a force platform have been objects of investigation in the literature.

The evaluation of elderly subjects with and without risk of falls, characterizing them by balance measures, is necessary for specifically determining the best measures to prevent falls and the risk of morbidity and mortality among the elderly. Thus, the aim of this study was to evaluate whether elderly with increased risk of falls have also an increased postural balance deficit quantified by means of a force platform during a one-leg stance balance test and to verify the relationship between the balance variables of the force platform and the score of a falls questionnaire.

\section{Methods}

This was a cross-sectional study. The sample of this research was selected by convenience from an interdisciplinary project called the EELO project (Study on Aging and Longevity), which was developed at the University of Northern Paraná (Unopar), after approval by the Research Ethics Committee of that institution (\# PP0070/09). Additional information is available at: http://www2.unopar.br/sites/eelo/.

Ninety-four elderly subjects were recruited voluntarily and randomly via registration in the Family Health Program (FHP) in the city of Londrina (PR). Inclusion criteria were: 1 ) elderly (over 60 years old); 2) physically independent, classified at levels 3 and 4 of the Functional Status scale proposed by Spirduso (8); and 3) in agreement to participate voluntarily in the study. Exclusion criteria were: presenting any kind of mental or physical illness that would interfere in the tests during the evaluation. For the balance measures in particular, the exclusion criteria were: 1) having suffered some type of surgery of the locomotor system; 2) having severe disorders of the musculoskeletal system (paresis or plegia, for example); 3) difficulty in maintaining a one-leg stance (one foot); 4) lacking good cognitive status evaluated by the mini-mental state examination - mini mental (good score > 17) (9).

The participants answered a questionnaire on the risk of falls proposed by Downton (10) through a structured interview. The questionnaire aims to identify the factors that predispose to falls in the elderly, considering history of falls, medication use, sensory changes (visual and auditory), motor disorders in lower limbs, mental confusion, and gait disturbance. Each item displayed in the scale corresponds to a point, the higher the score, the greater the risk of falls. Individuals with higher scores on two points are identified as individuals at high risk of falls. After evaluating the risks of falls, subjects were divided into two groups: G1 control group (low risk of falls) and G2 group (high risk of falls).

The postural balance was quantified using the BIOMEC400 force platform (Figure 1), developed in Brazil by EMG System of Brazil Ltd (SP). The platform is able to quantify the distribution of vertical force on 4 points for analysis of postural balance. The platform signs of reaction, after filtered, are analyzed by Matlab routines program with the system software itself, which extracts the main parameters of postural balance: pressure center displacement area (COP), average frequency and average speed postural sway of the COP in both directions of movement (anteroposterior: $\mathrm{A} / \mathrm{P}$ and mediolateral: $\mathrm{M} / \mathrm{L}$ ). Both evaluations, the falls questionnaire and balance, were performed on the same day when the elderly individuals visited the institution, and all experimental procedures were performed by the same raters (11). 
The elderly were familiarized with the equipment and the experimental protocol. The balance test occurred in a suitable environment, with individuals instructed to remain in a one-leg stance condition (lower limb preferably) on the force platform, with bare feet, arms loose and relaxed beside the body and the head positioned horizontally with respect to the ground. The test was performed using the experimental protocol, eyes open, requesting that individuals observe a target (black cross $=14.5 \mathrm{~cm}$ height $\mathrm{x} 14.5$ $\mathrm{cm}$ wide $\mathrm{x} 4 \mathrm{~cm}$ thick) wall mounted at eye level and $2 \mathrm{~m}$ away. Three trials of 30 seconds with 30 seconds rest were performed. The average of the three measurements was used for analysis (12)

Statistical analyses were performed using the Statistical Package for Social Sciences (SPSS) version 20.0 , using $5 \%$ significance $(\mathrm{P}<0.05)$. The distribution of the data was verified by Shapiro-Wilk test. Since the force plate data were not normally distributed, they are presented by median and interquartile range.

Student's t test for independent samples was used to compare anthropometric variables of the two groups (G1 and G2). We used the Mann-Whitney test to compare the groups in relation to the rest of the variables. Finally, Spearman correlations were performed between the two variables (platform and questionnaire).

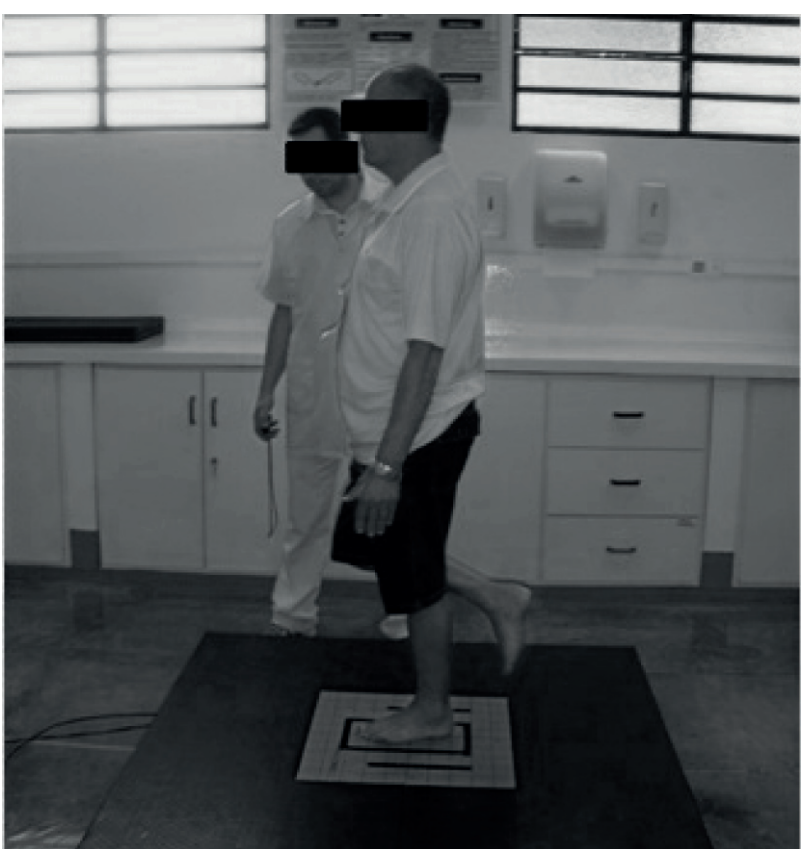

Figure 1 - Postural balance assessment in one-leg stance condition on the force platform

\section{Results}

Of the ninety-four elderly subjects, 34 (36.17\%) were male, and of these, 21 were in the low risk of falls group (G1) and 13 were in the high risk of falls group (G2). No differences were observed between the groups regarding gender distribution (chi square, $\mathrm{P}=0.08$ ).

Ages ranged from 60-84 years old. The average in G1 was 68 years old and in G2 was 69 years old, with no significant difference between them. Also, no significant difference between groups was found for weight variables, height and BMI according to Student's t test for independent samples ( $\mathrm{P}>0.05)$. The descriptive data of the groups regarding the distribution by gender, age and anthropometric characteristics are presented in Table 1.

Regarding postural balance, significant differences $(\mathrm{P}<0.05)$ were found between the groups (G1 and G2) for all parameters of the force platform, as shown in Table 2. In general, G2, considered the group most at risk of falls, also showed greater postural instability during the one-leg stance balance test, compared to the group with a lower risk of falls (G1), as presented in Table 2.

The results of rho correlations ranged from 0.17 to 0.29 , suggesting a weak relationship between the measures. In general, as the values for the history of falls increased the A-COP values also increased in the same direction, suggesting postural instability. Specifically, the correlations of the platform variables with the score for risk of falls were: A-COP $0.22(\mathrm{p}=$ $\left.0.006^{*}\right)$, VEL-AP $0.19(p=0.068)$, VEL-ML $0.29{ }^{*} p=$ $\left.0.005^{*}\right)$, FM-AP $0.21\left(\mathrm{p}=0.041^{*}\right)$, and FM-ML of 0.17 $(\mathrm{p}=0.102)$.

\section{Discussion}

Based on the results of this study, the group with an increased risk of falls (G2) showed a higher deficit of postural balance, quantified by the force platform in a one-leg stance. Note that currently, the force platform is considered the gold standard for analysis of postural balance disorders through valid and reliable parameter estabilographic measures, such as the frequency and COP displacement speed $(12,13)$.

Some studies have been performed to differentiate postural balance and risk of falls in the elderly, but for the majority the assessment of postural 
stability is made by a supporting bipedal test (14). Although interesting as a task, the bipedal support does not reflect all the difficulties of the postural control system for maintaining proper posture balance as performed in a one-leg stance condition, which may be similar to some tasks of daily living (climbing stairs, stages of travel) when the transition from a double support to only one leg is realized. It should be noted that the assessment of single leg support applied in this study to be more predictive of falls has applicability in the evaluation process and for intervention with physically independent elderly in rehabilitation programs for improving their balance and neuromuscular function (15).

Table 1 - Distribution of gender, age and anthropometric characteristics (weight, height and body mass index) in the study groups (Gl: without risk and G2: the risk of falls)

\begin{tabular}{|c|c|c|c|}
\hline Variables & Gl & G2 & \\
\hline & Mean (SD) & Mean (SD) & $\mathrm{p}$ \\
\hline $\operatorname{Sex}(n)$ & $M=(21) / F=(26)$ & $M=(13) / F=(34)$ & 0.080 \\
\hline Age & $68(5)$ & $69(6)$ & 0.271 \\
\hline Weight & $66(14)$ & $67(13)$ & 0.804 \\
\hline Height & $1.58(0.10)$ & $1.55(0.08)$ & 0.109 \\
\hline BMI & $26(4)$ & $27(4)$ & 0.175 \\
\hline
\end{tabular}

Note: Mean values with Standard Deviation in parenthesis (SD). $n=$ number of subjects; $M=$ male; $F=$ female. BMI = body mass index. Significant differences $p<0.05$.

Table 2 - Comparison between groups of postural balance measures through force platform

\begin{tabular}{lccc}
\hline \multicolumn{1}{c}{ Variables } & Gl & G2 & \\
\hline & Median $\left[1^{\left.\text {st } Q-3^{\text {rd }} \mathbf{Q}\right]}\right.$ & Median $\left[1^{\text {st } Q-3} 3^{\text {rd }} \mathbf{Q}\right]$ & p \\
\hline A-COP $\left(\mathrm{cm}^{2}\right)$ & $10.01[6.3-34.9]$ & $16.21[21.01-96.01]$ & $0.007^{*}$ \\
Velocity AP $(\mathrm{cm} / \mathrm{s})$ & $3.69[1.66-9.14]$ & $4.17[2.97-15.61]$ & $0.006^{*}$ \\
Velocity ML $(\mathrm{cm} / \mathrm{s})$ & $3.92[1.2-4.19]$ & $4.77[2.44-7.79]$ & $0.005^{*}$ \\
Frequency AP $(\mathrm{Hz})$ & $0.88[0.31-2.11]$ & $1.03[0.63-2.41]$ & $0.042^{*}$ \\
Frequency ML $(\mathrm{Hz})$ & $1.06[0.35-2.1]$ & $1.15[0.74-2.33]$ & $0.005^{*}$ \\
\hline
\end{tabular}

Note: Data presented in median and interquartile range [25 - 75]. G1 = without risk of falls $(<2)$; G2 = with risk of falls $(>2)$; AP $=$ Antero Posterior; ML $=$ Medio Lateral. *Significant differences $\mathrm{P}<0.05$. Mann-Whitney test.

The elderly in this study were characterized by high and low risk of falls using the Downton scale (10). This scale is useful because the items report aspects of previous falls, drugs, sensory and motor deficits, mental state and gait. All these factors are associated with the daily reality of the elderly population. Interestingly, the content of the scale can reveal a health problem, with physical and functional consequences for the elderly. The scale is sensitive to the main factor for falls in the elderly, postural imbalance. The results of this study support the hypothesis that the elderly with a high risk of falls also have greater postural instability.

Rosendahl et al. (16) and Bugdayci et al. (17) showed the importance of evaluations with the Downton scale (10) for predicting patients with risk of falls and thus outlined a treatment plan for them, aimed at preventing falls for this study population. Vellas et al. (18) highlighted among self-reported 
variables the history of falls in the previous year $(\mathrm{RR}=1.86095 \% \mathrm{CI} 1.519$ to 2.276$)$ as one of the determining variables for predicting recurrence of falls in the elderly. The experience of a previous fall with serious consequence such as a fracture, seems make the elderly more vulnerable to new episodes.

According to Rebelatto et al. (19), environmental risk can also be another determining factor for falls in the elderly, for example, slippery surfaces, no handrails, shelves very high, very high bus steps, among others. On the other hand, many elderly people suffer falls through use of medications, since many drugs, such as psychotropic drugs (antidepressants, antipsychotics, anxiolytics, anticonvulsants and mood stabilizers), can cause a balance deficit, increasing the risk of falls. There are reports that drugs can reduce supplementary motor area activity, which plays an important role in motion planning, especially in tasks involving motor coordination (20). Thus, although the use of medications may influence the incidence of falls, this variable is already considered in the range of the Downton questionnaire and therefore does not represent a limitation.

Sensory and cognitive aspects in postural control depend on a complex interaction between the neural and musculoskeletal system (21). The nervous system uses sensory information in the development of motor commands to regain balance. These commands are modulated by sensory characteristics and also by mechanisms related to attention, experience and context. The success of postural control depends on the flexibility and adaptation of sensory organization and neuromuscular strategy feedback and/or maintaining balance with feed-forward. The elderly have a decrease in proprioceptive acuity and physical abilities, which contributes to postural instability and the occurrence of falls (22).

Cognitive ability, as well as the delay of sensory and motor responses, may also influence balance $(23,24)$. In addition, the decrease in muscle mass and strength are important aspects that lead to a reduction in the ability to promote joint torque of the muscles involved in carrying out tasks such as: elevating from a chair, climbing stairs and maintaining balance while avoiding obstacles. In this context, these changes, in addition to causing more dependence for the individual, can facilitate falls. It is noteworthy that falls can happen due to bone and/or muscle weakness, or by a "sudden illness", or "drop attack" (25, 26). It generally occurs during normal activities, such as walking or changing position.
The difficulties in neuromuscular responses of the elderly found in the present study were indicated by the force platform parameters. These parameters characterize the necessary postural adjustments in strength and proprioceptive reflex response to maintain a proper posture balance (27). The present study showed that individuals predisposed to suffer falls or to have repeated falls in the future have higher values compared to the control group characterized by lower risk of falls. In addition, the data from this study reinforce the contribution of the Downton scale to assessing the risk of falls when there is an absence of high-tech equipment for discrimination of individuals at risk of falling. The scale was sensitive for discriminating the two groups (higher and lower risk) allowing evidence that those most susceptible to falls also had high values for all the force platform parameters associated with the COP for balance analysis. The literature also shows similar results to those found in the present study, indicating that the balance test is multifaceted and each evaluation has its particularity $(28,29,30)$.

Finally, it should be noted that the results of this study cannot be generalized to all elderly, those with or without musculoskeletal diseases and other chronic problems that come with age. Only COP parameters were measured and only one experimental condition of balance, so one cannot generalize to other functional tasks of balance and other decisive actions with neuromuscular deficits.

\section{Conclusion}

This study showed that the Downton scale is sensitive for detecting individuals who potentially would suffer falls or have recurring falls, since the group of elderly patients with increased risk of falls also showed greater postural instability, as certified by all balance parameters of the force platform. However, the correlations between variables were weak. The findings of this study have implications for public health, since this scale could be adopted in primary health care in order to predict the risk of falls in the elderly.

\section{Acknowledgement}

We thank the National Foundation for the Development of Private Higher Education (Funadesp, 
Brazil) for financial support with scholarships and research incentives.

\section{References}

1. Instituto Brasileiro de Geografia e Estatística. Censo Demográfico 2010. Rio de Janeiro: IBGE; 2010.

2. Mendes ACG, Aurélio de Sá D, Miranda GMD, Lyra TM, Tavares RAW. Assistência pública de saúde no contexto da transição demográfica brasileira: exigências atuais e futuras. Cad Saúde Pública. 2012;28(5):955-64.

3. Martin GB, Cordoni Júnior L, Bastos YGL. Aspectos demográficos do processo de envelhecimento populacional em cidade do sul do Brasil. Epidemiol Serv Saude. 2005;14(3):151-8.

4. de Oliveira MR, da Silva RA, Dascal JB, Teixeira DC. Effect of different types of exercise on postural balance in elderly women: a randomized controlled trial. Arch Gerontol Geriatr. 2014;59(3):506-14.

5. Gazzola JM, Perracini MR, Ganança MM, Ganança FF. Fatores associados ao equilíbrio funcional em idosos com disfunção vestibular crônica. Rev Bras Otorrinolaringol. 2006;72(5):683-90.

6. Maciel ACC, Guerra RO. Prevalência e fatores associados ao déficit de equilíbrio em idosos. Rev Bras Ci e Mov. 2005;13(1):37-44.

7. Clifford AM, Holder-Powell H. Postural control in healthy individuals. Clinic Biomech. 2010;25(6): 546-51.

8. Spirduso WW. Dimensões físicas do envelhecimento. São Paulo: Manole; 2005.

9. Hughes MA, Duncan PW, Rose DK, Chandler JM, Studenski SA. The relationship of postural sway to sensorimotor function, functional performance, and disability in the elderly. Arch Phys Med Rehabil. 1996; 77(6):567-72.

10. Downton JH. Falls in the elderly. London: Edward Arnold; 1993.

11. Gil AWO, Oliveira MR, Coelho VA, Carvalho CE, Teixeira DC, da Silva RA. Relationship between force platform and two functional tests for measuring balance in the elderly. Rev Bras Fisioter. 2011;15(6):429-35.
12. da Silva RA, Martin B, Parreira RB, Teixeira DC, Amorim CF. Age-related differences in time-limit performance and force platform-based balance measures during one-leg stance. J Electromyogr Kinesiol. 2013; 23(3):634-9.

13. Lafond D, Corriveau H, Hebert R, Prince F. Intrasession reliability of center of pressure measures of postural steadiness in healthy elderly people. Arch Phys Med Rehabil. 2004;85(6):896-901.

14. Michikawa T, Nishiwaki Y, Takebayashi T, Toyama Y. One-leg standing test for elderly populations. J Orthop Sci. 2009;14(5):675-85.

15. Lord SR, Sherrington C, Menz HB. Falls in older people: risk factors and strategies for prevention. New York: Cambridge University; 2011.

16. Rosendahl E, Lundin-Olsson L, Kallin K, Jensen J, Gustafson Y, Nyberg L. Prediction of falls among older people in residential care facilities by the Downton index. Aging Clin Exp Res. 2003;15(2):142-7.

17. Bugdayci D, Paker N, Dere D, Özdemir E, Ince N. Frequency, features, and factors for falls in a group of subacute stroke patients hospitalized for rehabilitation in Istanbul. Arch Gerontol Geriatr. 2011;52(3):215-9.

18. Vellas JB, Wayne SJ, Garry PJ, Baumgartner RN. A twoyear longitudinal study of falls in 482 communitydwelling elderly adults. J Gerontol A Biol Sci Med Sci. 1998;53(4):M264-74.

19. Rebelatto JR, Morelli JGS. Fisioterapia geriátrica: a prática da assistência ao idoso. Barueri: Manole; 2007.

20. Charansonney O. Physical activity and aging: opposing physiologic effects. Ann Cardiol Angeiol. 2012; 61(5):365-9.

21. Carvalho RL, Almeida GL. Aspectos sensoriais e cognitivos do controle postural. Rev Neuroc. 2009; 17(2):156-60.

22. Jang YC, Van Remmen H. Age-associated alterations of the neuromuscular junction. Exp Gerontol. 2011; 46(2-3):193-8.

23. Mahoney JR, Holtzer R, Verghese J. Visual-somatosensory integration and balance: evidence for psychophysical integrative differences in aging. Multisens Res. 2014;27(1):17-42. 
24. Borel L, Alescio-Lautier B. Posture and cognition in the elderly: interaction and contribution to the rehabilitation strategies. Neurophysiol Clin. 2014;44(1):95-107.

25. Fischer BL, Gleason CE, Gangnon RE, Janczewski J, Shea T, Mahoney JE. Declining cognition and falls: role of risky performance of everyday mobility activities. 2014;94(3):355-62.

26. Brito TA, Coqueiro RS, Fernandes MH, de Jesus CS. Determinants of falls in community-dwelling elderly: hierarchical analysis. Public Health Nurs. 2014; 31(4):290-7.

27. Parreira RB, Boer MC, Rabello L, Costa VS, de Oliveira E, da Silva RA. Age-related differences in center of pressure measures during one-leg stance are time dependent. J Appl Biomech. 2013;29(3):312-6.
28. Pollock AS, Durward BR, Rowe PJ, Paul JP. What is balance? Clin Rehabil. 2000;14(4):402-6.

29. Kirchner M, Schubert P, Getrost T, Haas CT. Effect of altered surfaces on postural sway characteristics in elderly subjects. Hum Mov Sci. 2013;32(6):1467-79.

30. Mancini M, Horak FB. Effect of altered surfaces on postural sway chacteristics in elderly subjects. Hum Mov Sci. 2013;32(6):1467-79.

Received: 07/03/2013

Recebido: 03/07/2013

Approved: 01/22/2015

Aprovado: 22/01/2015 